\title{
Key considerations when developing a risk management framework for tailings facilities
}

\author{
AG Gagnon Lundin Mining Corporation, Canada
}

\begin{abstract}
Risk management is a key component of any effective corporate tailings governance framework. Uncertainty is inherent to a mining company's business activities and may present both risk and opportunity. An integrated risk-based approach assists management in identifying, evaluating, prioritising and managing key risks to the achievement of the mining company's strategic objectives, as well as opportunities to enhance performance and value.

Corporate risk management frameworks are typically designed to manage risks at the enterprise or operational level with specific definitions for consequence and likelihood. Challenges can develop in accurately ranking tailings-related risks when utilising an operational-level corporate risk management framework. This paper highlights various corporate risk management approaches and discusses some key considerations when developing a tailings risk management framework and governance model.
\end{abstract}

Keywords: risk management, tailings, governance, framework, corporate strategy

\section{Introduction}

Tailings management facilities can represent a significant environmental liability for a mining company. Tailings dam failures over the last few decades have led to loss of life, environmental impacts, significant financial costs to mining companies, governments, and society, and the less tangible impact on the mining industry's reputation and social licence to operate. Tailings management facilities are a business risk and there is increasing recognition throughout the industry that their management is a core business function for mining (Davies \& Dumaresq 2018).

The risks associated with tailings facilities can vary widely and span across most, if not all, functional business areas of a mining company. Risk management is a key component of any effective corporate governance framework for tailings facilities. A comprehensive risk management framework ensures that risks are minimised to acceptable levels and aligned with the mining company's strategic objectives. Internal governance frameworks are unique for most mining companies due to variances in business objectives, organisational structure, risk capacity and appetite, stakeholders, jurisdictions, and regulatory requirements. Despite these variances, there are some fundamental components that should be included when developing a corporate risk management framework for tailings management facilities.

In an attempt to learn from past events, and thereby avoid costly failures, mining companies are seeking information on how to be more effective at identifying and managing tailings management risks. There is no lack of information on risk management: a simple Google search for the term 'risk management' generates over 650 million results. To make sense of the wide variety of information available, this paper highlights how some companies are approaching tailings risk management and discusses some key considerations when developing a tailings risk management framework and governance model. 


\section{Risk management frameworks}

Risk management is an integral part of a mining company's processes and systems. It is not a standalone activity performed by a select group or in respect of specific areas or domains. Managing risk is part of the responsibilities of every employee, as each employee's efforts support the strategic objectives of the business. It is vital that a logical alignment exists between risk management and strategic business objectives or goals (Passenheim 2010).

"In a well-functioning, truly enterprise-wide risk management system, all major risks would be identified, monitored, and managed on a continuous basis" (Stulz 2008).

When companies consider how to manage risk, they must deal with two main concepts: risk capacity and risk appetite. Risk capacity relates to the company's objectives and the amount of risk it can take on in meeting those objectives. For example, a common business objective is to grow shareholder value. In the pursuit of this objective, the organisation might take on some debt to fund various greenfield or brownfield capital projects. The amount of debt that the company can take on will be a certain percentage of its capital structure. The higher the percentage, the higher the company's risk capacity for taking on debt. On the other hand, risk appetite determines how the company's risk capacity is utilised (Mark 2011).

Considering risks is necessary in the pursuit of business objectives, and risk identification and assessment must be integral to the company's planning and operational and business development decisions and processes. To ensure a comprehensive assessment of risk exposures, it is necessary to establish the context in which the company operates. This means defining the external and internal factors that need to be considered when identifying, assessing and managing risks.

Risk management tools and structures are important elements of a risk management strategy, but they may not be sufficient in isolation. An appropriate risk management strategy should pay close attention to the incentives of the company's various internal and external stakeholders, and how those biases drive decisionmaking.

External factors include external stakeholders (including relationships with and perceptions of), local, national and international environments (legal, regulatory, economic, socio-political, etc.), industry-specific (e.g. competition), technological, natural (e.g. seismicity, precipitation), and any other external factors that may impact the company's business objectives. Internal factors speak to internal stakeholders, the company's approach to governance (including company structure, standards, policies, objectives, roles and responsibilities, accountabilities, decision-making processes, etc.), contractual relationships, internal capabilities (including intellectual and financial capital, technology, and systemic resources), and culture. All of these factors are considered in defining the scope of the company's risk management program.

Companies are more likely to look at risk management reactively where the framework requires decisionmakers to follow a step-by-step process to set a context, evaluate the issue, determine the risks, identify and communicate with stakeholders, perform analysis, implement changes and continually monitor and report (Mark 2011). In addition to requiring a set of tools, firms typically rely on risk management structures, such as the board of directors and committees focused on risk, audit and compliance.

Some common frameworks that are used as a starting point when developing an enterprise risk management system include International Organization for Standardization (ISO) 31000 Risk Management Guidelines (ISO 2018) and Committee of Sponsoring Organizations (COSO) of the Treadway Commission (COSO 2017) Enterprise Risk Management - Integrating with Strategy and Performance.

The principles and generic guidelines set forth in ISO (2018) follow a widely-accepted plan-do-check-act model for the design, implementation, monitoring and review, and continual improvement of an integrated enterprise-wide risk management framework. Managing risk is based on the principles, framework and process as illustrated in Figure 1. 
A three-part solution to develop an effective risk management system includes (Kaplan \& Miles 2016):

1. Agree on business objectives, mission, values, and priorities.

2. Formulate company's risk capacity and appetite. Risk appetite clarifies what risks can be accepted and left unattended, and which ones need immediate action.

3. Continuous monitoring and bench marking against risk appetite.

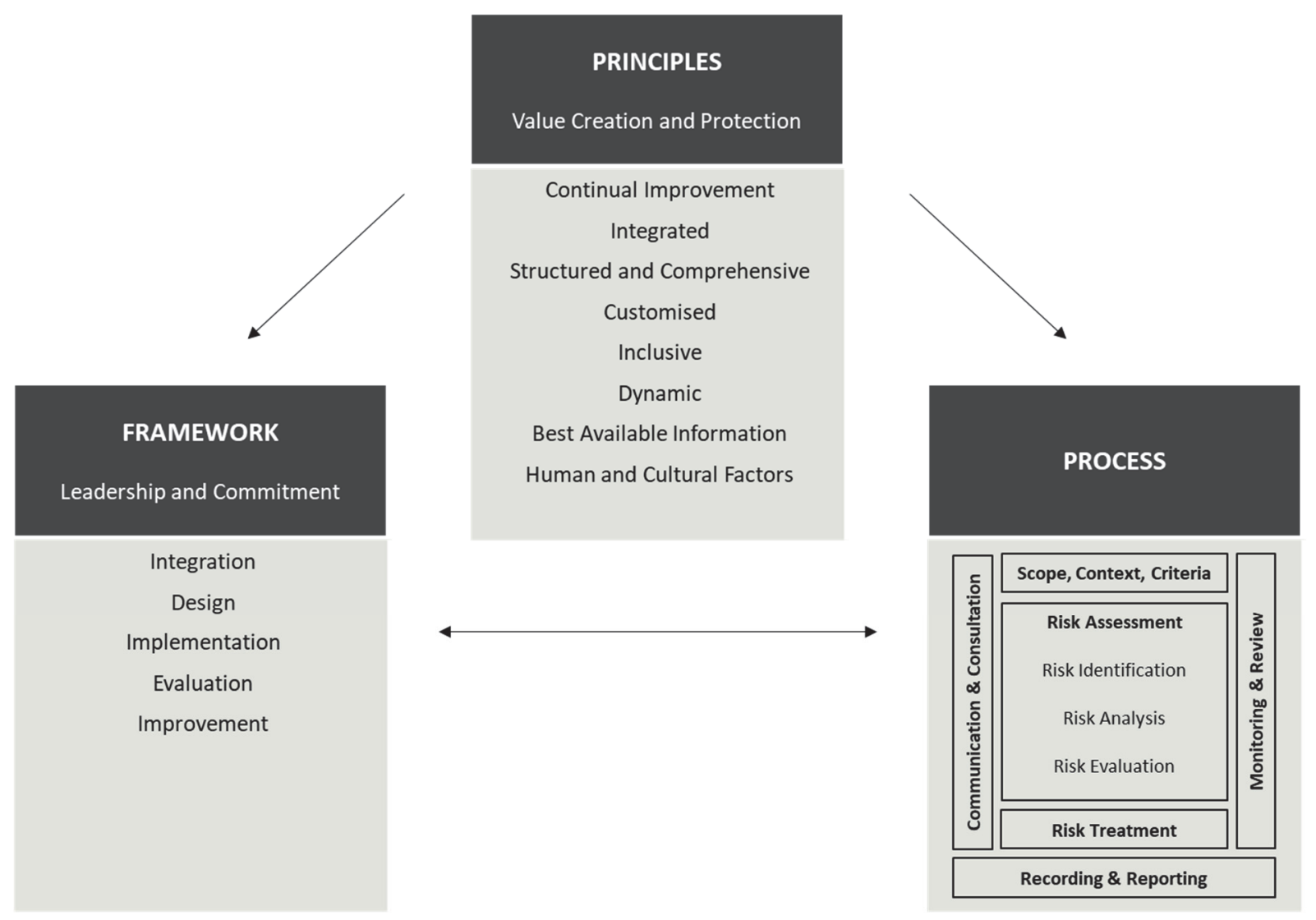

Figure 1 Relationships between the risk management framework, principles and process (after ISO 2018)

The ISO 31000 framework is common amongst mining companies because it not only manages risk on a strategic enterprise level, but it also deals with the risks at operational management levels. ISO 31000 can also be used by any organisation regardless of its size, activity or sector. Using ISO 31000 can help organisations increase the likelihood of achieving objectives, improve the identification of opportunities and threats and effectively allocate and use resources for risk treatment (ISO 2018).

The COSO (2017) framework, as shown in Figure 2, supports optimisation of internal checks and alignment towards the company's objectives or goals, within the scope of the internal monitoring system. The framework clarifies the importance of enterprise risk management in strategic planning and embedding it throughout an organisation because risk influences and aligns strategy and performance across all departments and functions.

The five components of the COSO (2017) framework include governance and culture, strategy and objective setting, performance, review and revision, and information, communication, and reporting. Within these five components are 20 key principles.

Both frameworks emphasise that managing risk is an integral part of decision-making throughout an organisation and vital for carrying out its mission and improving performance. Both frameworks also recognise that risk and uncertainty are important considerations as leaders form strategy, run operations and deliver project initiatives. The following section introduces how tailings risk management can be performed within these overarching frameworks. 


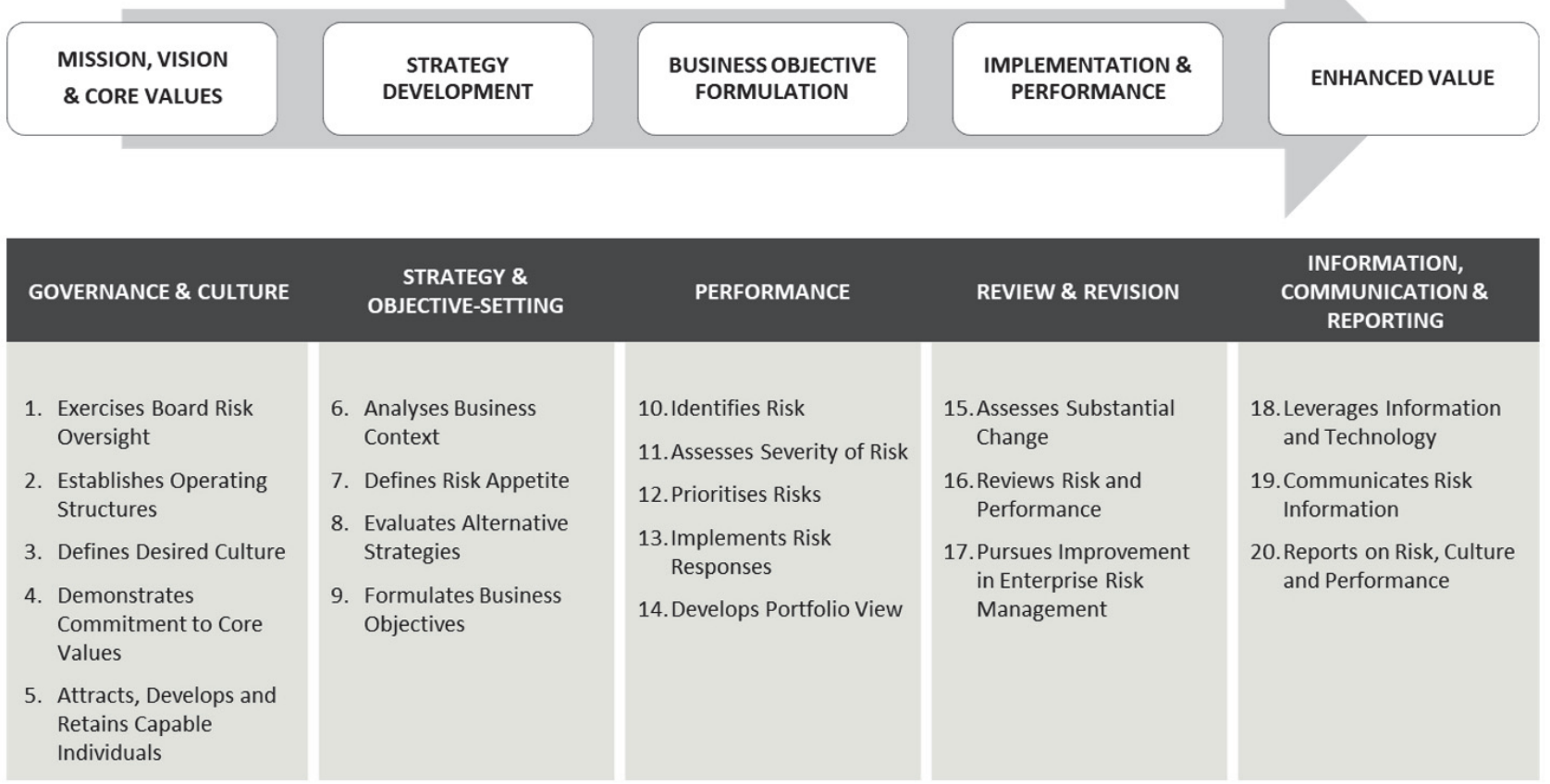

Figure 2 COSO's enterprise risk management framework (after COSO 2017)

\section{Tailings risk management: a general approach}

\subsection{Overview}

This section presents a general approach and some key considerations when developing a tailings risk management framework that aligns with the company's enterprise risk management (ERM) framework. Figure 3 presents a general step-by-step process for a comprehensive tailings risk management framework.

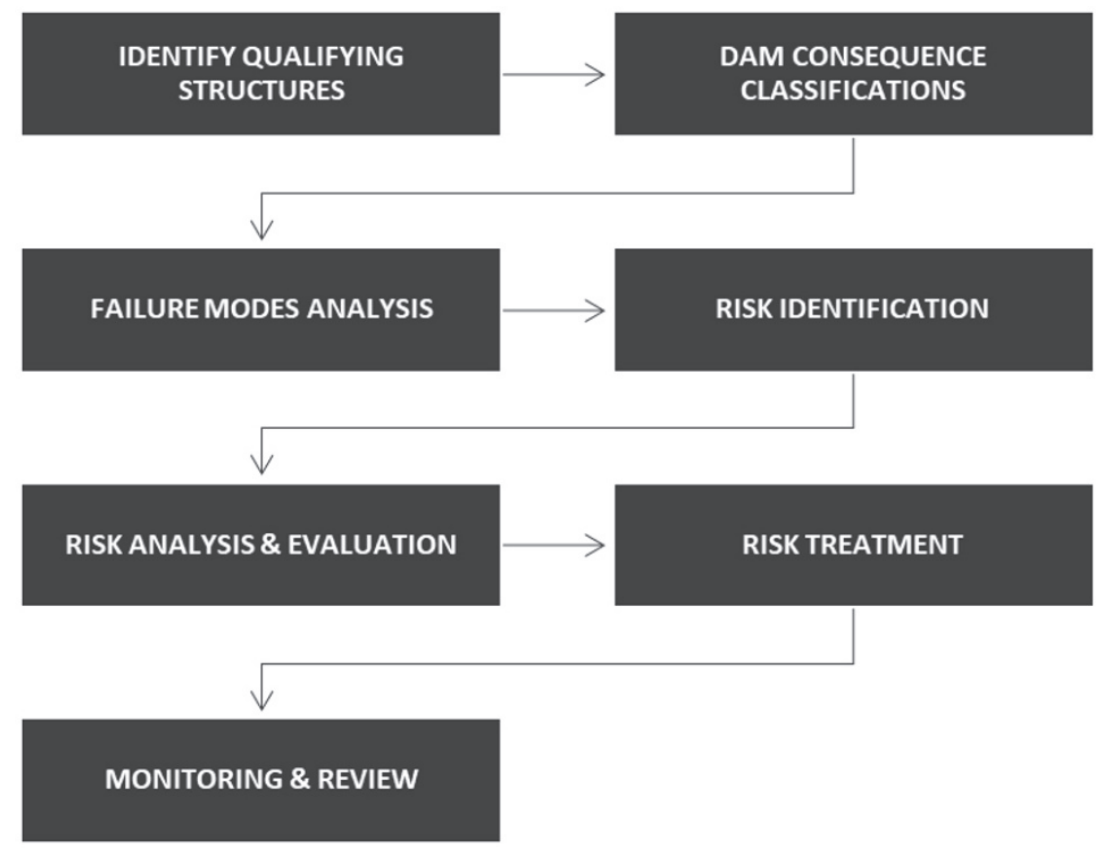

Figure 3 General step-by-step process for a comprehensive tailings risk management framework 
This process can be performed for active and inactive sites with qualifying dam structures. This process can also be adapted and used on sites without qualifying structures such as filtered tailings stack facilities or subaqueous former open pit disposal facilities.

\subsection{Inventory of qualifying structures}

One of the first steps in tailings risk management is to define what a qualifying structure is and then identifying all qualifying tailings and water retaining structures at each site. The Canadian Dam Association (CDA) Dam Safety Guidelines (CDA 2013) defines a dam as "a barrier constructed for the retention of water, water containing any other substance, fluid waste, or tailings, provided the barrier is capable of impounding at least $30,000 \mathrm{~m}^{3}$ of liquid and is at least $2.5 \mathrm{~m}$ high". The definition may be expanded to include dams less than $2.5 \mathrm{~m}$ in height or impounding less than $30,000 \mathrm{~m}^{3}$ where the consequences of failure are likely to be unacceptable to the public. The definition for dam can vary depending on the jurisdiction so the CDA definition should be used in addition to other applicable definitions.

Once established, the dam inventory can form the basis for planning, risk management, operational controls and reporting. The site inventory should contain the following information at a minimum:

- Structure location, function and geometry.

- Dam consequence classifications.

- Contact information.

- Status of supporting documentation.

- Dam safety inspection and dam safety review frequency.

\subsection{Consequence classifications}

The method of assessing the consequence classification or hazard rating for a tailings management facility is an essential tool in developing an understanding of the consequences of a tailings dam failure. Hazard is defined as the potential consequence that would arise from a dam failure and does not consider the probability or likelihood of a failure (International Commission on Large Dams 2011).

Since dam classification systems vary across jurisdictions and some jurisdictions are without their own classification system, a typical approach by mining companies is to develop a corporate technical standard that requires the use of one system at a minimum across all sites unless the local jurisdictional requirements are more stringent. For Canadian-based mining companies, it is typical to use the CDA (2013) guidelines or an adapted version with more conservative design criteria across all sites. Using the CDA framework allows a mining company to be able to catalogue and compare the ratings for all its dams at all its facilities worldwide.

Internal corporate dam classification systems are also used at some mining companies. These systems typically include consequences to company production and reputation since CDA and other equivalent systems are focused more on impacts to the public and other stakeholders outside of the mining company.

\subsection{Failure modes analysis and risk identification}

Following the dam consequence classifications, a tailings-focussed risk assessment workshop can take place to assess failure modes, complete the overall risk evaluation process, and create a working tailings risk register. Potential failure modes should be pre-screened in advance of the tailings risk assessment workshop. Failure modes should be tailored to the site by drawing upon the workshop participant's experience, observed site conditions, and several reference documents (CDA 2013; Environmental Agency 2011; Federal Emergency Management Agency 2016; McKenna 2002). During the risk workshop, all pre-screened failure modes should be reviewed. Typical workshop participants should include tailings operations and environmental site managers, corporate tailings manager or director, Engineer of Record, and independent tailings and geotechnical experts. 
Failure modes analysis (FMA) (Federal Energy Regulatory Commission 2018) can be used to classify each pre-screened failure mode for each of the selected qualifying structures (typically dams with a high consequence or greater, according to CDA dam safety guidelines). This FMA can then be used to screen the Category 1 related risks according to the Federal Energy Regulatory Commission (2018) and identify those that will be subject to analysis and evaluation. Category 1 potential failure modes are considered of greatest significance considering need for awareness, potential for occurrence, magnitude of consequence and likelihood of adverse response.

\subsection{Risk analysis and evaluation}

A failure modes and effects analysis (Vick 2017) can be used to assess likelihood, consequence, and risk for each failure mode identified from the FMA that was classified as a Category 1. The existing corporate enterprise-wide risk matrix can then be used for definitions of likelihood and consequence.

Corporate risk management frameworks are typically designed to manage risks at the enterprise or operational level. Supporting corporate risk registers used during risk analysis and evaluation include specific definitions for consequence and likelihood. Challenges can develop in accurately evaluating tailings-related risks when utilising a risk register that has short (less than five years) operational focused timeframes for likelihood. If the corporate likelihood rating system is focussed more on operational issues and does not include low-likelihood ratings more appropriate to dam safety, modifications or extensions can be performed by extrapolating ratings from the base corporate matrix based on expected value or $\mathrm{f}-\mathrm{n}$ curves (Whitman 1984). This modified risk rating matrix allows a more critical examination of low-likelihood and high consequence risks.

The risk workshop participants can then work through each highlighted failure mode for each facility or structure, rating the likelihood and consequences, and noting what controls are already in place and what controls need to be added. Failure modes can be grouped together for efficiency during this process. The results for each failure can then be plotted on the corporate base risk matrix and modified risk matrix with the extrapolated values for low-likelihood events.

A limitation to this approach is that the workshop does not constitute a comprehensive dam safety risk assessment, which is typically conducted over several days and attempts to identify and examine all potential pathways to dam failure using detailed event trees. This approach also only focuses on geotechnical dam safety failure modes; mainly the potential for catastrophic breach and loss of contents (water and/or tailings) from behind the dam. There are other failure modes related to environmental protection, health and safety, constructability, costs, operations, and closure that can also be assessed. An alternative approach is to include all other potential failures modes and have a multi-disciplinary participant list during the workshop. These approaches can be combined and conducted in phases.

\subsection{Risk treatment, monitoring and reporting}

Risks that are rated at an unacceptable level based on the company's risk appetite and capacity should be included in a risk management plan. The objective of the risk management plan is to develop and apply compensation factors to reduce the levels of risks (International Commission on Large Dams 2011). Risks included in the management plan can be summarised and reported throughout the company using a risk summary card, which can be an effective tool for presenting high-level results to senior management. An example is shown in Figure 4. The summary card lists the practical effects of the risk event on operations, the likelihood, leading indicators, and mitigation actions. It also identifies who has primary ownership or accountability for managing the risk and who implements the mitigation plan. 


\begin{tabular}{|c|c|c|c|c|c|c|c|}
\hline $\begin{array}{l}\text { STRATEGIC } \\
\text { OBJECTIVE }\end{array}$ & $\begin{array}{l}\text { RISK EVENT \& } \\
\text { DESCRIPTION }\end{array}$ & $\begin{array}{l}\text { CONSEQUENCES } \\
\text { OR OUTCOMES }\end{array}$ & RISK INDICATORS & RISK RATING & $\begin{array}{l}\text { EXISTING } \\
\text { CRITICAL } \\
\text { CONTROLS }\end{array}$ & RISK OWNER & $\begin{array}{l}\text { MITIGATION } \\
\text { PLANS }\end{array}$ \\
\hline $\begin{array}{l}\text { Zero tailings } \\
\text { incidents }\end{array}$ & $\begin{array}{l}\text { Dam failure due } \\
\text { to weakened } \\
\text { foundation } \\
\text { conditions }\end{array}$ & $\begin{array}{l}\text { Loss of life } \\
\text { Environmental } \\
\text { harm } \\
\text { Mine shutdown } \\
\text { and production } \\
\text { losses } \\
\text { Reputation loss }\end{array}$ & $\begin{array}{l}\text { Trigger levels for } \\
\text { existing } \\
\text { instrumentation } \\
\text { Settlement or } \\
\text { observed surficial } \\
\text { deformation } \\
\text { during } \\
\text { inspections } \\
\text { Observed } \\
\text { seepage }\end{array}$ & 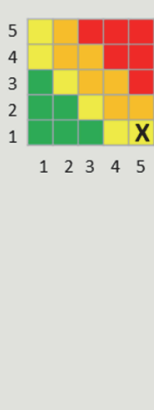 & $\begin{array}{l}\text { Instrumentation } \\
\text { Monitoring } \\
\text { OMS Manual } \\
\text { Inspections } \\
\text { Dam Safety } \\
\text { Inspections } \\
\text { External } \\
\text { independent } \\
\text { dam safety } \\
\text { reviews } \\
\text { Management } \\
\text { system reviews }\end{array}$ & Tailings Manager & $\begin{array}{l}\text { Site } \\
\text { investigations } \\
\text { Advanced } \\
\text { material } \\
\text { characterisation } \\
\text { tests } \\
\text { Expand } \\
\text { monitoring } \\
\text { network } \\
\text { Buttress } \\
\text { Pumping wells }\end{array}$ \\
\hline
\end{tabular}

Figure 4 Risk summary card example

Risk registers should be reviewed and updated at least quarterly by site and integrated into the strategic business planning process. It is important that these updates are shared with the central or corporate ERM team to ensure alignment across the company. An annual tailings risk management performance report should be prepared and shared with the board of directors and senior management.

\section{$4 \quad$ Governance model}

The board of directors has responsibility to ensure that a mining company's key risks are identified and appropriately managed. The board of directors and senior management agree on the company's mission and values, and management formulates strategic objectives consistent with them. These strategic objectives then underpin the functional and business unit operational objectives design to ensure the success of the company. An example of a governance model that can be used by a mining company to manage enterprise-wide risks is provided in Figure 5. This model identifies key roles at corporate, regional (if applicable), and site level. The regional level may not be required depending on the size and organisational structure of the company.

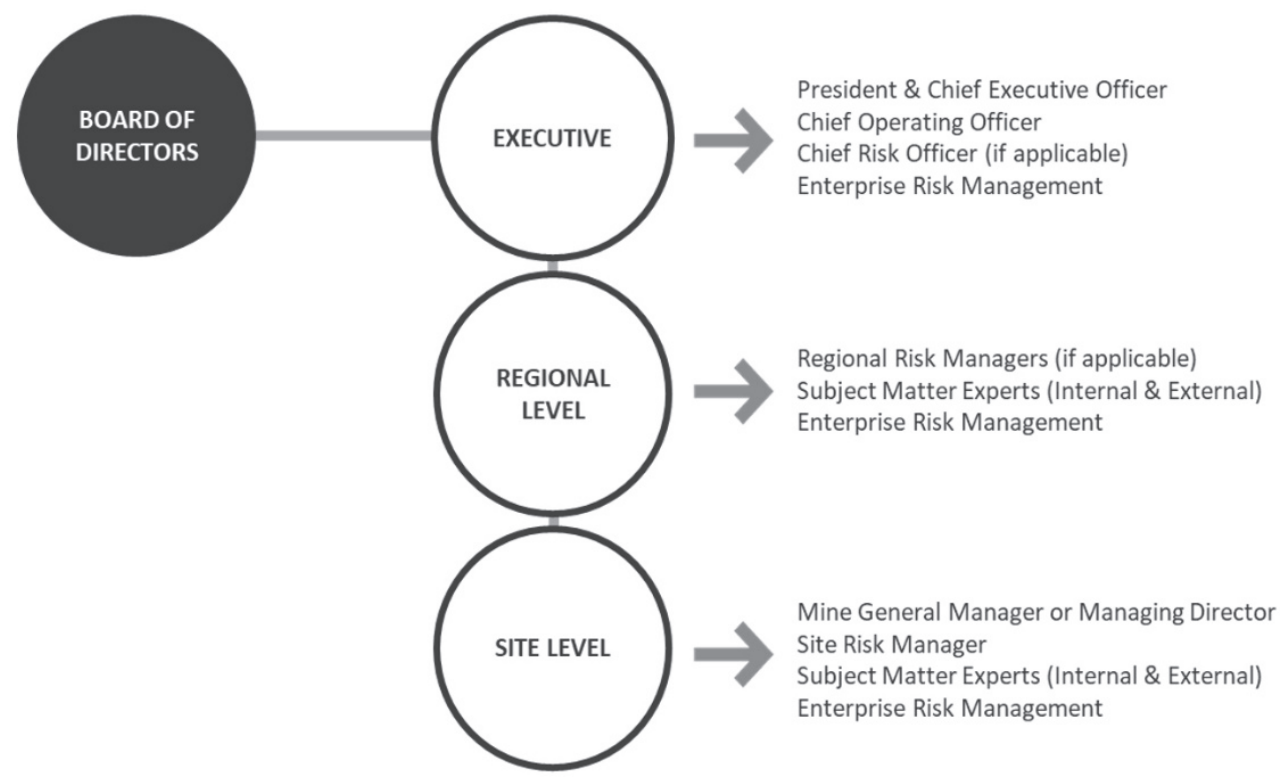

Figure 5 Example of a governance model for managing enterprise-wide tailings risks

The board of directors, together with senior management, ensure that an effective risk management framework is in place. The company's strategic and operational objectives are assessed for potential risk exposures and opportunities. The board of directors has the responsibility to identify and understand the principal risks of the business in which the company is engaged, to achieve a proper balance between the risks incurred and the potential impact on stakeholders, and to ensure that there are systems in place which 
effectively monitor and manage those risks with a view to the long-term viability of the company. This approach is predicated on ongoing communication and is designed to ensure alignment across the organisation.

The president and chief executive officer (CEO) of the company should have overall accountability for managing risk and ensuring the implementation and effectiveness of a risk management program. Together with the management team, the CEO is accountable for establishing an appropriate 'tone from the top' and promoting a strong risk management culture. The CEO, chief financial officer, and chief risk officer (if applicable) should be responsible for ensuring that management clearly defines and annually reviews a risk appetite statement for the organisation along with risk tolerance limits or capacity in respect of key business performance parameters that reflect the company's risk appetite.

The chief operating officer, vice presidents, and mine general managers (or managing directors) have overall accountability for risk management in their areas of responsibility and for ensuring managers are aware of, understand, and comply with risk management policies, standards and procedures.

\section{Conclusion}

Tailings management is a business risk and has become a core business function amongst leading mining companies. The risks associated with tailings facilities can vary widely and span across most if not all functional business areas of a mining company. A comprehensive risk management framework ensures that tailings risks are minimised to acceptable levels and aligned with the mining company's mission, values, and strategic objectives. A simplified risk management approach for tailings facilities must first identify what physical structures require managing followed by consequence classifications, FMA, risk mapping, and mitigation planning. This approach, supported by an efficient governance model with clear roles and responsibilities across the organisation, will produce a comprehensive risk management framework for tailings facilities.

\section{References}

CDA 2013, Dam Safety Guidelines 2007 (Revised 2013), Canadian Dams Association, Toronto.

COSO 2017, Enterprise Risk Management - Integrating with Strategy and Performance, Committee of Sponsoring Organizations of the Treadway Commission, viewed 1 March 2019, https://www.coso.org/Documents/2017-COSO-ERM-Integrating-withStrategy-and-Performance-Executive-Summary.pdf

Davies, M \& Dumaresq, C 2018, Mining Association of Canada's Guidance on Tailings Management, presented at Tailings and Mine Waste 2018, Keystone.

Environmental Agency 2011, Modes of Dam Failure and Monitoring and Measuring Techniques, Flood and Coastal Erosion Risk Management Research and Development Program Project SC080048/R1, Environment Agency, Bristol, viewed 1 March 2019, http://evidence.environment-agency.gov.uk/FCERM/Libraries/FCERM_Project_Documents/Report_Modes_and_Dam_Failure_ and_Monitoring_and_Measuring_Techniques.sflb.ashx, p. 15-73.

Federal Emergency Management Agency 2016, Pocket Safety Guide for Dams and Impoundments, Federal Emergency Management Agency, Washington, p. 80.

Federal Energy Regulatory Commission 2018, 'Dam safety performance monitoring program', Engineering Guidelines for the Evaluation of Hydropower Projects, US Federal Energy Regulatory Commission, Washington, p. 188.

International Commission on Large Dams 2011, ICOLD Bulletin 139: Improving Tailings Dam Safety - Critical Aspects of Management, Design, Operation and Closure, vol. 24, issue 1, p. 42.

ISO 2018, ISO 31000 - Risk Management, International Organization for Standardization, https://www.iso.org/iso-31000-riskmanagement.html

Kaplan, RS \& Miles, A 2016, Risk Management - the Revealing Hand, Working Paper 16-102, Harvard Business School, https://www.hbs.edu/faculty/Publication\%20Files/16-102_397b963b-1a8b-4dcf-942f-e45acc8c9e96.pdf

Mark, K 2011, An Overview of Risk and Risk Management, Richard Ivey School of Business, London.

McKenna, GT 2002, Landscape Engineering and Sustainable Mine Reclamation, PhD thesis, University of Alberta, Edmonton.

Passenheim, O 2010, Enterprise Risk Management, Ventus Publishing ApS, Frederiksberg.

Stulz, R 2008, 'Risk management failures: what are they and how do they happen?', Journal of Applied Corporate Finance, vol. 20, no. 4, pp. 39-49.

Whitman, RV 1984, 'Evaluating calculated risk in geotechnical engineering', Journal of Geotechnical Engineering, vol. 110, issue 2, pp. 143-188.

Vick, SG 2017, Risk Analysis: How Did We Get Here and Where Are We Going?, presented at 2017 Alberta Dam Safety Seminar, viewed 1 March 2019, http://aep.alberta.ca/water/programs-and-services/dam-safety/documents/RiskAnalysis-Presentation-Apr242017.pdf, p. 4. 